\title{
Prevalence of sexually transmitted disease among male patients presenting with proctitis
}

\author{
H ANDREWS, J WYKE, M LANE, J CLAY, M R B KEIGHLEY, \\ AND R N ALLAN \\ From the Departments of Gastroenterology and Genito-Urinary Medicine, General Hospital, Birmingham
}

SUMMARY Fifty male patients with proctitis were examined and the clinical, microbiological, serological and proctological features compared with 51 known male homosexuals attending the genitourinary (GU) clinic at the same hospital. The homosexuals had a short history of bowel symptoms, minor sigmoidoscopic and histological changes on rectal biopsy and many positive serological markers of sexually transmitted infection. There was some evidence of sexually transmitted disease in the IBD patients and three were homosexuals. IgG antibodies were positive for chlamydia trachomatis $(n=10)$ and hepatitis $A(n=7)$. One had a positive screening test for syphilis. Stool examination and rectal swab cultures were positive in two patients for cryptosporidium and cytomegalovirus respectively. Gastroenterologists must be aware of the possibility of specific infection in IBD patients and a clinical history should include sexual preferences and practices. If homosexuality is admitted, specific infection must be sought and excluded.

There has been an increased awareness in recent years of the large number of organisms that can be spread by the sexual practices of homosexual men. ${ }^{1}$

The prevalence of conventional sexually transmitted disease such as gonorrhoea and syphilis has increased recently together with diseases such as Shigella, Salmonella and the Campylobacter species, and parasites such as Giardia lamblia and Entamoeba histolytica. ${ }^{2-6}$ Proctitis without specific infection has been reported recently in $15 \%$ of homosexual men attending a sexually transmitted disease clinic. ${ }^{7}$ The emergence of the acquired immunodeficiency syndrome, caused by the HIV virus (human immunodeficiency virus), has heightened concern amongst specialists in all fields and particularly in gastroenterology.

This study evaluates the prevalence of sexually transmitted disease among 50 men attending an inflammatory bowel disease or rectal clinic with proctitis (IBD patients) compared with 51 known homosexual men attending the Genito-Urinary Department of the same hospital.

Methods

PATIENTS

Fifty consecutive new referrals to the inflammatory

Address for correspondence: Dr R N Allan, FRCP, Dept of Gastroenterology, The General Hospital, Steelhouse Lane, Birmingham B4 6NH.

Received for publication 2 September 1987. bowel disease or rectal clinics with sigmoidoscopic evidence of proctitis between May 1985 and May 1986 were studied (age range 16-72, mean 39 years). They were compared with a consecutive group of 51 self-referred male homosexuals seen by one of us (HA) in the Genito-Urinary Medicine clinic (age range 17-64, mean 31 years).

All patients were interviewed by one doctor (HA) who worked in both the genitourinary and inflammatory bowel disease clinics. A detailed history was taken which included the nature of the gastrointestinal symptoms and a personal health questionnaire of marital status, number of children, use of illicit drugs, particularly intravenous drugs, previous attendance at a sexually transmitted disease clinic and homosexual experience. If the patient was homosexual his number of partners and sexual practices were ascertained.

Blood was taken for serological tests to detect syphilis, chlamydia trachomatis, hepatitis A and B and HIV antibodies. Syphilis was assessed using Treponema pallidum haemagglutination tests (TPHA) and Venereal Disease Research Laboratory test (VDRL). Chlamydia was evaluated using a microimmunofluorescent test which was also the technique used for detection of hepatitis A and B. Human immunodeficiency virus antibodies were detected using the ELISA test for immunofluorescent antibodies.

Rectal swabs were taken for culture of Neisseria 
gonorrhoea, herpes simplex virus and Chlamydia trachomatis. For Neisseria gonorrhoea the culture media used was VCNT $10 \%$ lysed horse blood agar on Columbia media containing Vancomycin $3 \mu \mathrm{g} / \mathrm{l}$ to inhibit staphylococcus, streptococcus and other Gram positive organisms. Colistin $125000 \mu / 1$ was added to inhibit Gram negative organisms other than Neisseria gonorrhoea ( $E$ coli and Klebsiella). Nystatin $12500 \mu / 1$ was added to inhibit yeasts and Trimethoprim $5 \mu \mathrm{g} / 1$ to inhibit proteus.

Herpes simplex was identified by viral isolation in tissue cell culture. Chlamydia trachomatis was also identified in tissue cell culture media. A sample of stool was obtained for culture and microscopy. Sigmoidoscopy was performed and a macroscopic grading used with a range $0-3$ where 0 was normal, 1 mild reddening only, 2 obvious reddening with contact bleeding, 3 severe reddening with excess mucus bleeding and/or ulceration.

STATISTICAL ANALYSIS

Differences between the two groups were assessed using Fisher's exact test.

\section{Results}

There was no significant difference between the ages of the patients in the two groups (Fisher's exàct test NS).

\section{IB D PATIENTS}

Three of the IBD patients admitted to being homosexual. One 72 year old had ceased sexual activity five years earlier when his lifetime partner had died. One practiced fellatio only but with a large number of partners. The third homosexual engaged in active and passive anal intercourse, fellatio, and anilingus. None of the patients had used illicit drugs. Five patients admitted to having attended a sexually transmitted disease clinic. One homosexual attended regularly for review and four other heterosexual men had been treated previously for non-specific urethritis.

The mean duration of symptoms among the IBD patients was five years (range 8 months-16 years).

\section{HOMOSEXUAL GROUP}

Forty five of 51 homosexuals admitted to active and passive anal intercourse, fellatio, and anilingus. Fourteen of the 51 homosexuals had bowel symptoms of rectal irritation and/or diarrhoea usually of short duration (mean six months, range one week-12 months). None had attended a gastroenterologist or disclosed these symptoms to their general practitioner.
Table 1 Positive results of rectal swabs, cultures, stool microscopy, and histology

\begin{tabular}{lll}
\hline & $\begin{array}{l}\text { IBD patients } \\
n=50\end{array}$ & $\begin{array}{l}\text { Homosexual 'controls' } \\
n=51\end{array}$ \\
\hline Rectal swabs & & \\
Gonorrhoea & 0 & 1 \\
Chlamydia trachomatis & 0 & 2 \\
Herpes simplex virus & 0 & 3 \\
Stool microscopy/histology & & \\
Cryptosporidium & 1 & 2 \\
Entamoeba coli & 0 & 2 \\
Cytomegalic virus & 1 & 0 \\
Total & 2 & 10 \\
\hline
\end{tabular}

$\mathrm{p}<0.02$ (Fisher's exact test).

RECTAL SWABS AND STOOL MICROSCOPY

The results of rectal swab culture and stool microscopy in both groups are shown in Table 1.

Of the homosexual group one had gonorrhoea and herpes simplex virus on culture of rectal swab and two other homosexuals had urethral gonorrhoea although their rectal swabs were negative. Rectal swab culture was negative in all IBD patients.

SIGMOIDOSCOPIC APPEARANCES

Seven of the 51 homosexuals refused sigmoidoscopy. The sigmoidscopic appearances in the remaining 44 patients compared with the IBD patients is summarised in Table 2.

HISTOLOGICAL FIN DINGS

Histological examination of the rectal biopsies confirmed the diagnosis of proctitis in all the IBD patients. None had spirochaetosis. Histological examination of rectal biopsies was normal in 27 of the 44 homosexuals with mild superficial inflammatory mucosal change in eight, spirochaetosis in five, melanosis coli in one. In three patients the appearances were consistent with non-specific proctitis where bowel symptoms had been present for six, 10 , and 12 months respectively.

SEROLOGICAL TESTING

The results of serological testing are summarised in

Table 2 Macroscopic sigmoidoscopic appearances

\begin{tabular}{llll}
\hline Grade & $\begin{array}{l}\text { IBD patients } \\
n=50\end{array}$ & $\begin{array}{l}\text { Homosexual 'controls' } \\
n=44\end{array}$ & $p$ values \\
\hline 0 & 6 & 27 & $<0.001$ \\
1 & 7 & 17 & $<0.001$ \\
2 & 16 & 0 & $<0.001$ \\
3 & 21 & 0 & $<0.001$ \\
\hline
\end{tabular}

Macroscopic appearances graded normal to severe (0-3); (Fisher's exact test). 
Table 3 Positive serology-IgG antibodies

\begin{tabular}{llll}
\hline & $\begin{array}{l}\text { IBD patients } \\
n=50\end{array}$ & $\begin{array}{l}\text { Homosexual 'controls' } \\
n=51\end{array}$ & $p$ values \\
\hline Chlamydia & 10 & 20 & $<0 \cdot 02$ \\
Syphilis & 1 & 11 & $<0 \cdot 001$ \\
Hepatitis A & 7 & 8 & NS \\
Hepatitis B & 0 & 14 & $<0 \cdot 001$ \\
HIV & 0 & $4^{*}$ & $<0 \cdot 02$ \\
\hline
\end{tabular}

${ }^{*}$ Four positive of 33 patients tested; (Fisher's exact test).

Table 3. The IBD patient with positive VDRL for syphilis was referred to the genitourinary department for further testing which was negative. Testing for HIV antibodies was only undertaken with informed consent. Thirty three of the 51 homosexual group agreed to be tested of whom four were positive. Twelve homosexual men had anti-HBs antibodies in their serum indicating past infection with hepatitis $B$ virus and two patients who were $\mathrm{HBs} \mathrm{Ag}$ positive also had 'e' antigen present.

\section{Discussion}

The ideal study would be one carried out in single, never married men attending the IBD clinic with acute problems compared with known homosexuals of a similar age. Because such a prospective study would take many years to complete, this study addressed the incidence of sexually transmitted disease among a consecutive series of IBD patients which is the particular concern of the practising gastroenterologist. Although the IBD patients had longer symptomatic histories than the homosexual group the age difference between the groups was not significantly different.

A number of specific infections may be confused with non-specific proctitis. Lymphogranuloma venereum (LGV) serotypes of Chlamydia trachomatis may cause severe inflammation of the rectum with fistulae, perianal abscesses and occasionally, strictures. These symptoms may cause confusion with Crohn's disease but, if the diagnosis is entertained, the obligate intracellular organisms can be isolated on the correct media. Serology is not helpful. None of the patients in this study with positive Chlamydial serology had organisms in their rectum causing proctitis.

Herpes simplex virus (type II) may cause proctitis but the severe anorectal pain, tenesmus and typical perianal lesions (papules, ulcers and crusts) serve to distinguish it from other causes. These perianal lesions yield virus for culture on the correct media. The three homosexuals with positive rectal swab culture for Herpes simplex in this study had severe anorectal pain and many perianal lesions.
Gonococcal proctitis is not usually confused clinically with inflammatory bowel disease since it rarely presents with symptoms which are common in IBD patients. Gonococcal proctitis was only identified in the homosexuals in this study as a result of contact tracing of homosexual men with acute gonococcal urethritis.

Viral hepatitis A and B is known to have a high prevalence in homosexual men compared with their heterosexual age matched counterparts. Hepatitis A $\mathrm{IgG}$ is found in up to $30 \%$ of male homosexuals compared with $12 \%$ in age matched heterosexuals. ${ }^{8}$ It was surprising and unexplained that the antibody prevalence was similar in the IBD patients and homosexual groups in this study.

Markers of hepatitis B infection are higher in male homosexuals $(30-50 \%)$ than in the general population $(5 \%)^{9}$ and this observation was supported in this study where the homosexuals have a prevalence rate of $28 \%$ of whom two patients were $\mathrm{HB} \mathrm{Ag}$ positive carriers.

Cryptosporidium is a protozoa which commonly causes infection in AIDS patients. ${ }^{10}$ In this study the two homosexuals with cryptosporidium on stool microscopy were both HIV antibody positive and the IBD patient with cryptosporidium had been on oral corticosteroids for some months. In adults cryptosporidium is a mild transient and selflimiting infection in the immunocompetent but severe, protracted and untreatable in the immunosuppressed. ${ }^{10}$

Cytomegalovirus (CMV) and herpes simplex virus may produce florid infection in the AIDS patient with ulceration anywhere in the gastrointestinal tract. ${ }^{11}{ }^{12}$ The one IBD patient in this study who showed cytomegalovirus on microscopy had been receiving oral corticosteroids.

Sexually transmitted disease was uncommon in the male IBD patients predominantly because only a small number of them were homosexual. The presence of proctitis certainly did not deter two of the three homosexuals from undertaking anal intercourse. The prevalence of sexually transmitted disease in IBD patients in this study may be less than elsewhere because the gastroenterology and genitourinary medicine units are on the same hospital site and self-referral to the genitourinary medicine clinic is encouraged. Studies from other hospitals in the city would be of particular interest as this is the only hospital with both units on the same site. Some of the clinical staff work in both units and this is well known in the relatively small, close knit homosexual community in Birmingham. Thus the homosexual patients with bowel symptoms tend to attend the genitourinary medicine clinic where they know they can obtain expert advice for both aspects of their problem. 
Although the homosexuals in this study tended to know the nature of their problem and undertook selfreferral to the appropriate clinic, three homosexuals previously unidentified did present to the IBD clinic. The sexual preference of a patient is not obvious by his appearance, dress, occupation or social class ${ }^{1}$ and physicians may be reluctant to ask this question. ${ }^{13}$

Further, many sexually transmitted diseases are asymptomatic and may be overlooked unless the appropriate microbiological and serological tests are undertaken. Infection with more than one organism is common and the rectal mucosa has a limited and non-specific histopathological and clinical response to many infections.

The gastroenterologists must be aware of the possibility of specific infections which can be elucidated with a detailed history including sexual preference and practices and, if homosexuality is admitted, a definite search must be made for organisms known to have a high prevalence in this population.

\section{References}

1 Zazal HL, Soln N, Carrasco JI, et al. The gay bowel syndrome. Clinicopathologic correlation in 260 cases. Ann Clin Lab Sci 1976; 6: 184.

2 Judson FN, Perley KA, Robinson ME, Smith JK. Comparitive prevalence rates of sexually transmitted disease. Am J Epidemiol 1980; 112: 836.

3 Bader M, Pederson AHB, Williams R, Spearman J, Anderson H. Venereal transmission of Shigellosis in Seattle, King County. Sex Trans Dis 1977; 4: 89-91.
4 Quinn TC, Godsell SE, Fennell C, et al. Infections with Campylobacter jejuni and Campylobacter-like organisms in homosexual men. Ann Intern Med 1984; 101: $187-92$.

5 Philips SC, Mildvan D, Williams DC, Gelb AM, White HC. Sexual transmission of enteric protozoa and helminths in a venereal disease clinic population. $N$ Engl J Med 1981; 305: 603-6.

6 Sargeaunt PG, Oates JK, McLennan I, Oriel JD, Goldmeier D. Entamoeba Histolytica in Male Homosexuals. Br J Vener Disease 1983; 59: 193-5.

7 McMillan A, Gilmour HM, Slatford K, McNeillage GJ. Proctitis in Homosexual Men. A diagnostic problem. BrJ Vener Disease 1983; 59: 260-4.

8 Corey L, Holmes K. Sexual transmission of hepatitis A in homosexual men. $N$ Engl J Med 1980; 302: 435-8.

9 Lim KS, Catterall RD, Simon R, Dane IS, Briggs M, Tedder RS. The prevalence of hepatitis $B$ in male homosexuals. J Infection 1979; 1: 1963.

10 Currant WL, Reese NC, Ernst JV, Bailey W, Haymen MB, Weinstein W. Human cryptospordiosis in immunocompetent and immunodeficient persons. $N$ Engl J Med 1983; 308: 1252-7.

11 Knapp AB, Horst DA, Eliopoulos G. Widespread cytomegalosis gastroentero-colitis in a patient with acquired immunodeficiency syndrome. Gastroenterology 1983; 85: 1399.

12 Gertler SC, Pressman J, Price T, Brozinsky S, Miyai K. Gastrointestinal cytomegalovirus infection in a homosexual man with severe acquired immunodeficiency syndrome. Gastroenterology 1985; 85: 1403-6.

13 Pauly IB, Goldstein SG. Physicians attitudes in treating male homosexuals. Med Aspects Hum Sexual 1972; 4: 27-45. 